\title{
Importance of Ethical Aspects for Decision-Making
}

\author{
Zdenek Dytrt \\ Associate Professor at Tomas Bata and Pardubice University, Czech Republic \\ Kladska 232, 0003 Hradec Kralove, Czech Republic \\ Tel: 420-724-046-976 E-mail: zdenek.dytrt@tiscali.cz
}

\begin{abstract}
Radomir Serek
PhD graduate of Tomas Bata University in Zlin, Czech Republic

CEET Service Partner Manager in Siemens Healthineers

Na strani 632, 74245 Fulnek, Czech Republic
\end{abstract}

Tel: 420-602-218-156Ｅ-mail: radomir.serek@volny.cz

Received: May 12, 2020 Accepted: June 8, 2020 Published: July 2, 2020

doi:10.5296/ber.v10i3.17292 URL: https://doi.org/10.5296/ber.v10i3.17292

\begin{abstract}
The management theory did not develop equally with the changes in technologies. The consequence of this shortcoming is a prevalence of quantitative management which puts an emphasis on the quantitative values. This represents a risk for the sustainable growth. Therefore, the managerial ethics, which biases qualitative values and attitudes, is important for the managers' decision-making. The effective decision-making process is further based not only on the manager's experience, which may lead to a certain routine, but also on the cooperation among the other departments and educational institutions. Furthermore, the successful innovations, which are often an outcome of the systemic and complex decision-making, require to follow certain rules during their implementation. A person may become an initiator, leader, subject or a consumer of the innovation and should be adequately prepared for all these roles. Despite the abrupt development in the technical areas there is not such progress in the humanities. Education is still more focused on the content and form (thus quantity) rather than on the applications and relations (quality).
\end{abstract}

Keywords: Innovation, Leadership, Managerial Ethics, Responsible Management 


\section{Introduction}

Decisions are an output and also an input of human activities in a business and private life too. Those who are not capable of making decisions for any reasons, may not have a full control of their activities. In a business environment decision-making manifests itself as dealing with the problems, which are a need, priority, favour or an interest of the individuals and the companies as a whole.

The theory of management has gradually evolved hand in hand with the experience which people gained during their lives. Each generation tried to recognize and evaluate the accomplishments earned as the results of decision-making processes. The management theory developed gradually as the experience and technological possibilities were growing during the time. Originally the pace, in which the knowledge and experience increased, was rather dependent on changes in natural conditions and how these were perceived and adopted by people. Abrupt changes in the development were catalysed by wars and the massive struggle to develop more efficient combat equipment. This has found its application, of course in an altered state of use, also in the times of peace. Evidence of it could be served by a fact how quickly the defeated parties were able to recover after both world wars. Experience of military innovators and designers has been capitalized also in the peaceful times. However, there was still a prevailing emphasis on quantity rather than quality, like in the war times. Thus, the sustainable development of society was not sufficiently respected (Csikszentmihalyi, 2000). The main purpose of the company's development was focused on the dynamics and benefits of quantitative values without enough respect to the qualitative content.

Decision-making processes, if they are to be useful for the desirable development of societies, shall respect the unity of quantity and quality, as well as the complexity of the existing relations and their context, which are related to the addressed problems. Non-complex decisions may reduce an effectiveness of management and may have a negative influence on the desirable development of the economy and on the whole climate of society. In the end it may result in the development of consumerism and clientelism, which would be spread within the business environment as well as in the public administration activities.

\section{Effective Decision-making Process}

"The usual shortcoming faced in business management is non-systemic and non-complex approach." (Konkolski, 2010). Development of management in a desired direction is closely connected with the development of other scientific disciplines. Their mutual interactions increase the complexity of management. Management theory and practice can be enriched by the cooperation with other scientific disciplines. Such systemic approach may lead to the higher quality outputs of decision-making processes. Conversely, non-systemic approach to decision-making process may lead to unsuccessful decisions or to the decisions that will not have a long lasting. Systemic approach to management should respect the findings of other scientific disciplines and should endeavour to find solutions which will represent win-win situations for both involved parties and at the same time will not harm a 3rd party (any other potential stakeholder). 


\section{Mll Macrothink}

Business and Economic Research

ISSN 2162-4860

2020, Vol. 10, No. 3

The effective decision-making processes should not be only based on the experience or the management skills of the people, who are making these decisions, but also should be inspired by the recent findings of the related scientific disciplines. Managers may be experienced enough to make a competent decision on their own, or they are aware of their knowledge gaps and should consult the problem and its possible solutions with the knowledgeable experts. It should be prevented an undesired situation when a manager does not have enough knowledge, but still possesses a strong belief about being able to make a competent decision by himself alone. With repeating the decision-making processes, especially if they deal with the same or similar problems, the experience grows and will become a good prerequisite for a better quality of the future decisions. This better quality is manifested not only with the less mistakes but also with the increased speed of the decision-making process. If the input criteria for the decision-making process are the same as in the previous case, then there is less need for an expert consultancy, and it may be sufficient to apply the same or similar decision pattern like before. The management experience grows with the amount of interactions, consultancies, decisions made, lessons learnt and so on. However, a certain effort should be applied in order to prevent a routine in the decision-making processes as well as in the management itself. The routine in management would prevent its further development in seeking even more efficient solutions or the means to achieve them. Initiating and maintaining a cooperation between the co-workers within one department but also among the other departments could be one of the means to prevent a routine in the management. Further, a cooperation with the education or other institutions could bring a required inspiration for the new strategic innovations.

Jack Welch, a former CEO of General Electric (GE) said: "If the rate of change on the outside exceeds the rate of change on the inside, the end is near." (Allison, 2014). Unfortunately, the speed of changes in the technological development sometimes exceeds the understanding and capabilities of the contemporary workers, as well as of their managers. Thus, it may happen that the companies implement the new technology, but it does not bring the desirable results, for instance an increase of the productivity. The reason could be an improper or wrong implementation, which could be originated in the poor understanding or wrong expectations from the new technology. In addition to that, the decision-making processes are complicated by the stagnating expertise of the workers and managers who do not get acquaintance with the newest technological trends. This would require a continuous self-education, which sets more effort in compare to sticking to the routine solutions and their repeated application.

A tendency to prefer less effort demanding ways or the shortcuts is symptomatic of a consumerism in general. Consequently, consumerist society, which consumes more than needed and with as less effort as possible, could be a reason why we prefer to benefit from the technological development, but we are less enthusiastic to improve human based management approaches. The cause of it should be probably sought already in that how we behave and educate the children. What kind of examples and behaviour patterns they receive from parents and teachers? What kind of tasks they receive from them and how they are monitored and mentored during their accomplishments? What kind of rules and constraints are applied? In a later age, this would be a role of the legislation. However, we should bear in 
mind that the legislation cannot embrace all possible scenarios and their nuances. Therefore, there should be always a place for moral principles, sown already in the childhood, which will fill the gaps and will act as a mental compass which leads us in the right directions. On the other hand, a poor education system, weak legislation and unstable political situation are not good prerequisites for the desirable development of the societies.

It seems important to bring innovation into decision-making processes that would respect ethical principles valid across the whole society. At the same time there should be concise but comprehensibly and understandably written legislation. This could contribute to a creation of new methods of educational processes, improve and stabilize interpersonal relationships, both in work and personal life, increase the perceived responsibility of individuals as well as the whole society. At the end this could provide the answers and solutions for the growing demands of society and limited resources on the planet. It is unfortunately not possible without an intensification of internal and external cooperation among theoretical fields and their cooperation with the practice.

Theory and practice of management and their cooperation, during addressing the problems, has a broader meaning. This cooperation provides the decision-maker with more decision options but also brings a higher quality to the decision-making process itself, which is reflected in the final decision too. This itself might be a certain prevention of the consumerism which puts emphasis on maximizing benefits for individuals.

The question is whether there are enough preconditions, attitudes and efforts to respect these responsible approaches. Or whether the opportunities and possibilities, which are characteristic for the leadership concept, are thoroughly described and explained in the theory, and sufficiently utilized in the practice. Leadership is sometimes referred to as "management of management" (Dytrt, Serek, 2020). However, originally this meaning was reduced to the management of human resources only. It was not meant for the organization management as the whole but was reduced to the people's management and the related processes.

The development of the company's management is in fact connected with the people. People are creators of inventions and implementers of innovations, not only in the company, but in their private lives too. This is also the reason of the complexity and the need of responsibility in decision-making processes. The decision as an outcome of man's decision-making process is a consequence of his free right and free will to make a decision. However, the decision-making autonomy in a combination with a lack of ethical attitudes and responsibility may lead to irresponsible decisions. The reasons could be various, starting with the lack of responsibility and ethical manners in the family and ending with the low or no support for the ethical attitudes in the whole society.

The change in the state of management theory and practice lies in the responsibility of all people. If this change is not executed in time, then the current development of quantitative management in the world economy will deepen the consumerism trends even more. Responsibility and its application in the leadership methods may revert or slow down the consumerism trends. Additionally, leadership may innovate the contemporary prevailing quantitative management with the principles of ethics and their application in the 
management practice.

Responsible management is schematically illustrated on the following Figure 1:

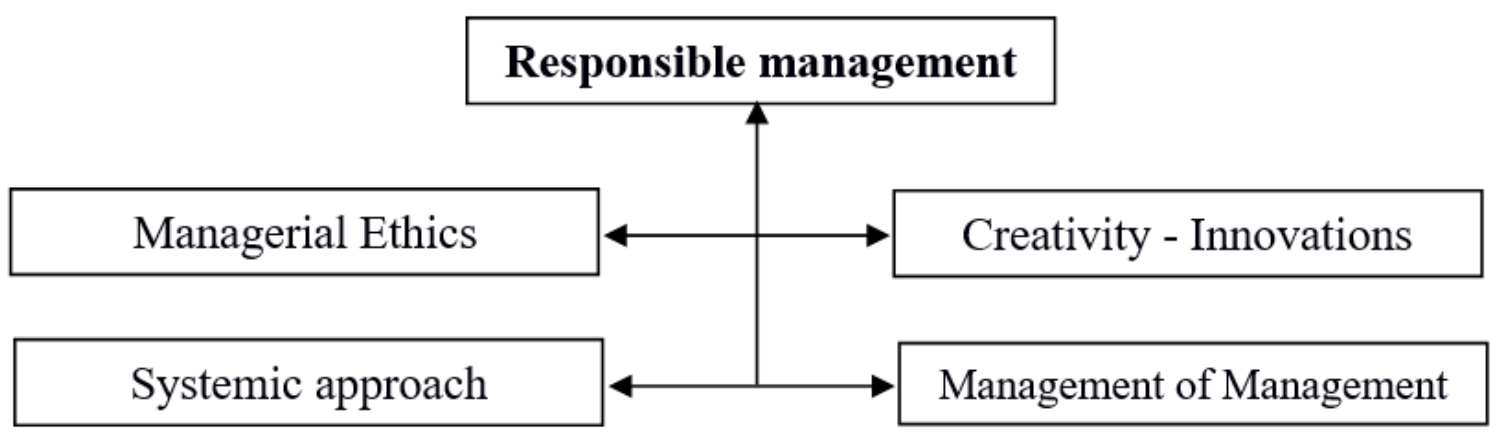

Figure 1. Responsible Management (Dytrt, 2015)

Responsible management is a contributing factor to the sustainable growth of the company, which is based on the principles of managerial ethics. The logic behind is formed around the fact that the development is based on applied innovations which lead to a change of the current state. Application of managerial ethics should be considered as an applied innovation in this respect, which should lead to the positive outcomes for the company as well as for the whole society. This in result, should contribute to the sustainable growth of both, company and the society.

Responsible management is manifested by decision-making, which is based not only on the quantitative values, but is also respecting an existence, importance and a need to apply qualitative values. This unity of quantity and quality determines the effectiveness and duration of the applied decisions. Purely quantitatively based decisions tend usually to win-lost scenarios and leave the other involved party in less favourable situation. This fact might be a reason why the win-lost based decisions are often a subject of re-negotiations and thus have a shorter duration than the decisions which are based on win-win situation for both involved parties.

\section{Essential Rules of Leadership}

Managerial ethics is a mean of the responsible management and a prerequisite of the responsible and effective decision-making about economic parameters which would bring the utility (win situations) for the whole society. This additionally requires respecting an existence of the inner qualitative values within the management, which is mostly addicted to the quantifiable parameters and to make decisions on the base of the derived quantitative indicators (Valenta, 2001).

Manager's decision-making should consider ethical values and this way achieve an equilibrium of quantity and quality, or so-called unity of quantity and quality. A simplistic example could be a decision about improving a profit and lost balance in order to deliver a higher value (dividends) to the shareholders. Manager may challenge sub-suppliers' prices 
(ask for discounts) or to replace long term suppliers with the new ones, which might be cheaper. Manager may even reduce some work positions or the salaries. At the same time, manager may even increase the prices of the production, provided there are still customers who will be willing to accept the new higher prices. This kind of solutions may really increase a profit in the short term. However, in the long term they may damage well established relationships with the suppliers, employees and the customers too. The root cause is that the manager was addicted to the quantifiable parameters (e.g. supplier prices, workers' salaries, production prices). Despite the manager's good intentions to improve profit and lost balance it might be that the manager has caused more damages in the long term. Thus, it is desirable to possess and respect an ethical compass (qualitative values) during the decision-making. This is a basis for the management concept of Leadership which parts are:

- unity of quantity and quality in management,

- management should be considered as management of the innovation process,

- managerial ethics - is a system of moral, competence and realization,

- the bearers of sustainable development are people, no other animal on the planet has such decisive role about the future of the planet like people,

- leadership expands the content and focus of the management,

- leadership is an intensification of the management due to its focus on people, relationships and qualitative values,

- thus leadership may be considered as a management of management, by taking the context and dependencies into account,

- leadership may be considered as an innovation of the management,

- leadership applies to everyone who manages (regardless if a company or just itself),

- leadership intensifies the social aspect (people are the subject as well as an object of the leadership),

- leadership brings a systemic approach, thus explores synergies which otherwise could be ignored or underestimated by the traditional management,

- leadership respects specific conditions - uniqueness of the managed object,

- leadership may prevent non-ethics and consumerism (Dytrt, 2015).

\section{Innovation - a Change in the Current State}

Innovation process has some similarities with the investment process. Both aims to change the current situation, and both requires a utilization of people, time and money. Investments may be subject to financial analysis, which includes cash flow from investing activities over the years, return of investment (ROI), return on invested capital (ROIC), thus all quantifiable parameters. On the other hand, financial impacts of the innovation are hardly to be forecasted. Nevertheless, in order to create prerequisites for the successful innovation process it is 


\section{Macrothink}

Business and Economic Research

ISSN 2162-4860

2020, Vol. 10, No. 3

desirable to follow certain rules which require a complex and strategic approach to decision-making and an effective preparation of a project. Important is also a good definition of the goals of the considered innovation. It is also required an ethical cooperation as well as an identification of the workers with the common values of the company or the project, in addition to their time and effort which they are supposed to invest to a preparation and a realization of the innovation. The workers contribute with their inventions to find and realize the solutions for the addressed problems. During that process they use a combination of the creative and critical thinking as illustrated on the Fig. 2.

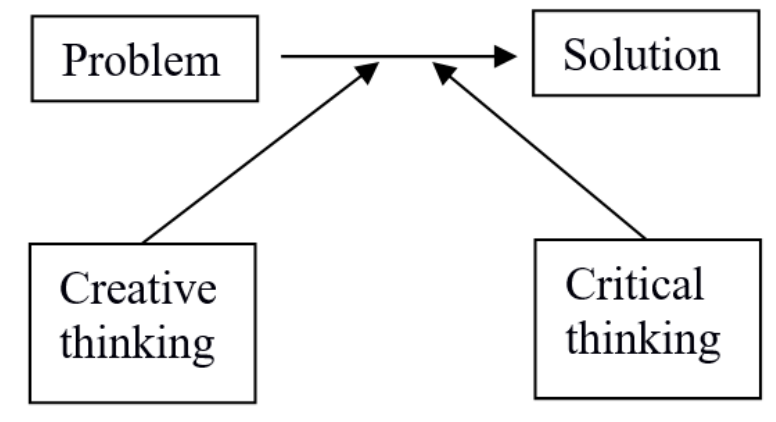

Figure 2. Invention process (Dytrt, 2015)

The successful invention process cannot do without the preparation and internal structuring. Disrespect to these facts would not secure a diligent invention process, which may lead to various failures and additional costs later. Aim of the internal structuring is to enable a balance between the creative and critical thinking. Critical thinking reduces failure rate of the future innovation projects. It prevents the potential mistakes during the realization, but also may completely stop some inventions to be realized.

\section{The structure (algorithm) of the innovation process:}

1) Preparation - the necessary information is collected, categorized and analysed. Categorization and analytical methods are defined. The scope of synthesis, characteristics of the addressed problem and the solution (the target state) are specified.

2) Maturation (incubation) - means a rational work with the collected information. Conditions of the solution and its realization are formed. Methods of intuition and association are used to seek for another possible solutions. Ideas undergo simulations in the real conditions and are evaluated in terms of their effectiveness.

3) Nativity (illumination) - the researcher (inventor, manager) comes to a specific form of invention. Critical thinking is applied, and the possible alternatives are sought. The inventions are then finalized and defined in their implementation variants and forms.

4) Authentication (verification) - Inventions are applied in their variants and forms. 
Their pros and cons are assessed in terms of the effectiveness. (Glaveanu, 2019)

\section{Rules of the Innovation Process}

The innovation process, in order to be successful, should follow the certain rules.

\subsection{Continuity}

It is about a permanent character of the innovation process which should continue, regardless the innovations may find themselves in the different stages, sometimes negative (requiring more efforts than provided outcomes) until they change to the positive outcomes, which will vanish one time in the future (Simpson et al., 2006). Thus, the innovation lifetime reminds a shape of sinusoid. It is desirable to have several innovations applied at one time in order to compensate their different effects.

Manager is supposed to be active in these three phases of the innovation as follows:

1) The manager issues an order to execute the innovation and cascade the concrete tasks to the subordinate management levels. Manager is preferably already involved in the innovation process from the begin, thus from the preparation phase. Therefore, the manager should be already well informed about the background, the purpose and the need of the innovation. This will help the manager to better control the change management process, which should be accompanied with the changes in the company.

2) Manager should create the conditions for the successful implementation of the innovation. Manager also deals with any problems which may raise during the implementation phase.

3) Manager should anticipate and forecast a moral wear (obsolescence) of the innovation and should prepare the prerequisites and conditions for the induced innovations which will bring the current innovation to the next higher level. Manager should set up the conditions to make this a continuous process (Dytrt, 2017). This will require a collaboration among the different departments within the company but also a cooperation with the educational institutions as well as with the research laboratories.

\subsection{Timeliness}

The rule of timeliness has much in common with the rule of continuity. The more emphasis is given to the time attributes and time stamps, in case of the timeliness rule. It is because the innovations are very sensitive to the right timing. Early or late timing of the innovation may reduce its effectiveness or even may lead to a longer time of anarchy (Dytrt, 2017). Thanks to the change management the time of anarchy can be reduced to an acceptable level and could be even used as a catalyst of the induced innovations, which will bring the original innovation to the next higher level.

\subsection{Complexity}

Non-complex innovations have mostly a reduced effectiveness (Dytrt, 2017). The reasons could be usually found in the insufficient analysis of the content and structure of the 
innovation factors and their interrelationships. These reasons may devalue not only the innovation but also the innovation process in the company as a whole and may reduce a trust of employees and managers in the new innovations. In the end, it may cause a certain disintegration of the management work. The prevention as well as a solution of the complexity could be seen in the innovation networks. Thus, in dividing the complex problems into the parts and assigning them to the competent divisions inside or even outside the company, in order to deal with them in a competent and complex way. This approach puts an emphasis on the close cooperation as well as the coordination of the different departments. Project management approach should be set in place to coordinate innovation networks effectively.

\subsection{Consistency}

The rule of consistency recalls a need of regular checks, whether the manager's decisions are diligently complied with, and to monitor the stage and effectiveness of the applied innovation. Methods of analysis and synthesis are utilized to interpret the measurable as well as unmeasurable values (Dytrt, 2017). Unmeasurable values (required quality) can be obtained through the managed interviews with the selected external customers or the internal technical experts. These interviews should be compared with the measurable values earned by the financial indicators and by the quantifiable customer surveys (for example a customer satisfaction index).

\section{Managerial Ethics in the Innovation and Decision-making Process}

The innovation process has its rules which, if not respected, may reduce an efficiency of the innovation process. Another supporting factor is a managerial ethics which increases a responsibility in decision-making processes as well as the transparency and integrity in the cooperation between the production and scientific fields. These aspects seem to bring more complexity to the innovation processes. However, this should be considered as good because the non-complexity of the innovation policy may reduce the effectiveness of economic and social development and to deepen bureaucracy.

The creation, development and implementation of the innovation as well as the ownership of its effectiveness is in responsibility of man. The final outcomes of the innovation process may be beneficial to society or, conversely, undesirable if the innovation process is misused to harm or disadvantage someone. Therefore, the managerial ethics should be an important part of the education process. It is desirable to intensify the knowledge of managerial ethics within the educational system. This should help to prevent the tendencies to overestimate an importance of quantification in the theory and practice of management.

Managerial ethics draws on the unity of quantity and quality. Decision-making processes, which are sourced in managerial ethics, have better prerequisites to prevent the undesirable problems from the very beginning of the invention. Thus, they are based more on the proactive approach rather than the reactive one. In combination with the higher complexity the ethical based decision-making processes may address the potential risks and problems already before they may arise and compromise or complicate the innovation process. 
The successful implementation of innovation depends on the quality of the decisions, to the certain extent. The success of the innovation will also vary according to the degree in which the principles of managerial ethics and the complexity of the innovation were respected. This could be already influenced by the preparation (education) in the families and schools. There is a difference if the children are taught to mechanically learn the facts or to be rather educated in the ways to find the reasons and possible applications of the things they are taught. At the same time, they should be provided with the ethical examples and see or feel that all non-compliant behaviours should be punished. This could prevent in the future that they would use shortcuts in a form of bribery or any other non-ethical behaviour, which would bring them the required results faster. They should contemplate the consequence and possible impacts of their doing not only on themselves but also on others and the society. This may help them in the future to be successful inventors or managers of the innovation process.

\section{Contribution of the Education System to the Ethical Decision-making}

Education system plays a significant role for ethics because it forms the moral values and principles which influence decision-making processes. Unfortunately, the taught content is highly and narrowly specialized, thus one discipline is isolated from another, although they converge in some extent and context. This not only influences the teaching process itself but also a development in both disciplines. For example, mathematics is taught at faculties of economics almost in the same extent as at the faculties of Mathematics and Physics in the Czech Republic. This may discourage some potentially talented economists to earn an academic title in this field. The cooperation between faculties and between the faculties and companies is still not on such level as it would be desired. The reasons could be in the mutual competition between the faculties and their departments.

Czech people sometimes confuse the teamwork with the work in the group, where they often compete instead of contributing together to the common target. Not coincidently the words "spolupráce" (cooperation) and "spoluprát se" (fight with each other) sound in the Czech language almost the same. The root cause of this behaviour could be perhaps found in the socialistic era when everybody was compelled to act in unison and vote for one communist party. Any deviance to this conforms was automatically considered suspicious and became a focus of the Czechoslovak State Security. This has changed with the velvet revolution which brought an opinion pluralism, promoted by the leader of the civil forum and the first post-communist president Václav Havel. Czech people started to enjoy the new earned freedom, open borders and were trying to act and look as different as possible from the others, perhaps as a compensation of the past years. The cult of the socialistic man was replaced with a cult of individualism which brought also undesired phenomena in the society, for example consumerism and clientelism. The first one was primarily influencing the people's acting, the second one was impacting the government's decisions and consequently also the legislation.

The lack of cooperation could be also sourced in the fear of the idea disclosure, so that it could be stolen, and the merits would be given to somebody else. The reasons could be rooted already in the school age. In the Czech schools, as well as in all the other post-communist countries, it is very common to copy or get some advice from the other, for example during 
the test, and cheat the teacher this way. It seems the cooperation is effective only if it is for the non-ethical purpose. It could be also a reason why these countries suffered from the very sophisticated corruption networks, especially in the first years of freedom. The situation is slowly improving, and the biggest corrupt people stand not only trial but goes also to the jail. The speed of positive changes could be faster if the unethical behaviour gets a zero tolerance already in the schools. The children should be taught from the young age that the cheating is not allowed, but the cooperation to earn positive outcomes from the teamwork is desirable for them and their team, as well as for the whole society. This cooperation should stick to the rules which are based in ethics and which help to win positive outcomes for all cooperating parties. The decisions, mainly those about strategic targets, may not work-out without the cooperation, or will not deliver their full potential.

\section{Conclusion}

Decisions and decision-making processes are the core of the company's and individual's management. Decision-making processes, in their form and content, may initiate and influence the changes in the current state of management theory and practice. These changes are desirable to address and deal with the challenges of individuals who are requested and supposed to make systemic and holistic oriented decisions, which may have an impact on the sustainable live or the development of society. There are advanced technologies which purpose is to facilitate decision-making processes. Unfortunately, these technologies rather contribute to the prevalence of the quantitative management. Quantitative management leads to a consumerism and a depletion of natural resources, which does not seem to be a good path to the sustainable growth. The sustainable growth will require a balance between the quantitative and qualitative values, thus so-called unity of quantity and quality, and the decisions which are based on the ethical principles.

Young generations should be taught already from the elementary schools to distinguish between ethically correct and incorrect decisions and actions. Parents and teachers should provide them with the right examples and should act as their first ethical examples (leaders) in a hope that some of the children will become real ethical leaders in their companies later. The current education systems should be analysed and innovated in order to better address the needs of the contemporary society. Instead of narrowly specialized subjects and focus on the mechanical learning (cramming) the education systems should focus more on how to use the earned knowledge practically and preferably in cooperation with other departments and colleagues. These principles are probably already implemented in the developed countries but are still not consistently applied in the post-communist countries.

Individualism in society is a consequence of quantitative management, which evokes the competitiveness, nevertheless in the range of quantitative values. It is a systemic violation of the unity of quantity and quality, which reduces the potential of the human effort. Due to an absence of managerial ethics in decision-making processes, society suffers from a development of consumerism, which could bring various forms of corruption, clientelism and consumerism. These phenomena are not desirable for the healthy business environment. Society should strive for the cooperative approaches which will bring positive values (wins) 


\section{IIMacrothink}

Business and Economic Research ISSN 2162-4860 2020, Vol. 10, No. 3

to all involved parties and at the same time will not harm any 3rd party (for example environment).

\section{References}

Allison, S. (2014). The Responsive Organization: Coping With New Technology and Disruption. [Online] Available:

https://www.forbes.com/sites/scottallison/2014/02/10/the-responsive-organization-how-to-co pe-with-technology-and-disruption/\#26368ace3cdd

Csikszentmihalyi, M. (2000). The Costs and Benefits of Consuming. Journal of Consumer Research, 27(2), 267-272. https://doi.org/10.1086/314324

Dytrt, Z. (2015). Odpovedny management. Praha: Management Press. p. 112.

Dytrt, Z. (2017). Kvantitativni management - cesta do konzumerizmu. Management v novych podminkach. Hradec Kralove: Prion. p. 17-27.

Dytrt, Z., \& Serek, R. (2020). Leadership - Management of Management. Business and Economic Research, 10(1), 274-289. https://doi.org/10.5296/ber.v10i1.16523

Glaveanu, V. (2019). The Creativity Reader. Oxford: Oxford University Press. p. 18.

Konkolski, S. (2010). Priciny a dusledky konzumu rizeni firmy. In Z. Dytrt et al. Manazerska etika - inspirace pro 21. stoleti. (pp. 102-103). Zilina: Georg.

Simpson, P. M., Siguaw, J. A., \& Enz, C. A. (2006). Innovation orientation outcomes: The good and the bad. Journal of Business Research, 59(10-11), 1133-1141.

https://doi.org/10.1016/j.jbusres.2006.08.001

Valenta, F. (2001). Eticky aspekt funkce manazera. In Z. Dytrt et al. Manazerska etika II inspirace pro 21. stoleti. (pp. 92). Praha: Economia.

\section{Copyright Disclaimer}

Copyright for this article is retained by the author(s), with first publication rights granted to the journal.

This is an open-access article distributed under the terms and conditions of the Creative Commons Attribution license (http://creativecommons.org/licenses/by/4.0/). 